\title{
Persistence of tumor necrosis factor inhibitor or conventional synthetic disease-modifying antirheumatic drug monotherapy or combination therapy in psoriatic arthritis in a real-world setting
}

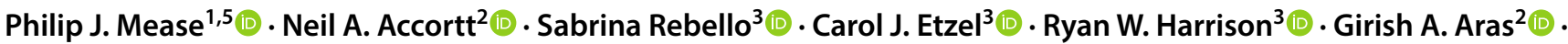 \\ Mahdi M. F. Gharaibeh ${ }^{2}$ (1) . Jeffrey D. Greenberg ${ }^{3,4}$ (D) David H. Collier ${ }^{2}(\mathbb{0})$
}

Received: 15 February 2019 / Accepted: 11 June 2019 / Published online: 18 July 2019

(c) The Author(s) 2019

\begin{abstract}
This study described treatment patterns in a psoriatic arthritis (PsA) patient registry for new or ongoing tumor necrosis factor inhibitor (TNFi) monotherapy, conventional synthetic disease-modifying antirheumatic drug (csDMARD) monotherapy, or TNFi/csDMARD combination therapy. This retrospective analysis included adults with PsA who enrolled in the Corrona PsA/ spondyloarthritis registry between March 21, 2013 (registry initiation), and January 31, 2017, and received an approved TNFi and/or csDMARD as "existing use" starting before registry entry or "initiated use" starting on/after registry entry. Therapy persistence was defined as index therapy use for $\geq 12$ months without a treatment gap of $\geq 30$ days. Among the evaluable patients with existing TNFi monotherapy ( $n=251)$, csDMARD monotherapy $(n=225)$, and combination therapy $(n=214)$, 93,87 , and $87 \%$ were persistent for $\geq 12$ months, and another 6,5 , and $5 \%$, respectively, had no change with $<12$ months of follow-up after first use. Among evaluable patients who initiated use of TNFi monotherapy $(n=26)$, csDMARD monotherapy $(n=35)$, and combination therapy $(n=15), 50,43$, and 53\% were persistent for $\geq 12$ months, and another 27,20 , and $20 \%$, respectively, had no change with $<12$ months of follow-up after first use. After initiation of index therapy, most changes (19-27\% of patients) were discontinuation; 4-13\% switched biologic therapy during follow-up. The results of this analysis of real-world treatment patterns in a PsA patient registry suggest that nonpersistence for TNFi monotherapy, csDMARD monotherapy, or TNFi/csDMARD combination therapy occurs more commonly after initiation of therapy than in patients with existing therapy. Trial registration: NCT02530268.
\end{abstract}

Keywords Psoriatic arthritis $\cdot$ Biological therapy $\cdot$ Tumor necrosis factor-alpha $\cdot$ Methotrexate $\cdot$ Antirheumatic agents

Elements of this work were published in an abstract for the European League Against Rheumatology 2018 Annual Meeting: https://doi.org/10.1136/annrheumdis-2018-eular.1929.

Electronic supplementary material The online version of this article (https://doi.org/10.1007/s00296-019-04345-1) contains supplementary material, which is available to authorized users.

Philip J. Mease

pmease@philipmease.com

1 Rheumatology Clinical Research, Swedish Medical Center/ Providence-St. Joseph Health, University of Washington, Seattle, WA, USA

2 Amgen Inc., Thousand Oaks, CA, USA

\section{Introduction}

Psoriatic arthritis (PsA)-a chronic, immune-mediated, inflammatory disease characterized by joint pain, swelling, and stiffness-is usually associated with psoriatic skin lesions [1]. Several treatment guidelines are available for PsA, including 2015 guidelines from the European League Against Rheumatism [2], 2015-2016 guidelines from the Group for Research and Assessment of Psoriasis and

3 Corrona, LLC, Waltham, MA, USA

4 Department of Medicine, New York University School of Medicine, New York, NY, USA

5 Seattle Rheumatology Associates, 601 Broadway, Seattle, WA 98122 , USA 
Psoriatic Arthritis [3], and 2017-2018 guidelines being developed by the National Psoriasis Foundation and American College of Rheumatology. Each recommends treatment options for PsA based on the severity of disease and its presentation. Mild PsA may respond to nonsteroidal antiinflammatory drugs or intra-articular corticosteroid injections. PsA that is moderate or severe, that does not respond to these therapies, or that involves domains such as dactylitis or peripheral arthritis may be treated with conventional synthetic disease-modifying antirheumatic drugs (csDMARDs) such as methotrexate, sulfasalazine, and leflunomide, but there are few clinical trials to support these therapies [2,3]. Alternatively, patients with dactylitis, peripheral arthritis, axial disease, or enthesitis may receive biologic treatment, usually with a tumor necrosis factor inhibitor (TNFi).

Several controlled clinical trials have shown the efficacy and tolerability of TNFi therapy in patients with moderateto-severe PsA, either as TNFi monotherapy or TNFi plus csDMARD in combination [4-9]. If TNFi treatment fails or is not appropriate, then newer therapies such as interleukin (IL)-12/IL-23 inhibitors, IL-17 inhibitors, abatacept, and tofacitinib may also be considered as alternatives [2, 3]. Published guidelines for PsA do not provide clear guidance on treatment pathways pertaining to restarting therapy after a treatment gap or switching between therapies.

The use of a disease registry to examine real-world treatment patterns can provide insight into whether initiation of treatment for PsA is consistent with the current guidelines and available clinical research. Understanding real-world treatment patterns may also inform future PsA treatment guidelines. Thus, the objective of this study was to describe treatment patterns for new or ongoing TNFi/csDMARD therapy in PsA patients participating in a nationwide registry.

\section{Materials and methods}

\section{Data source}

This was a retrospective analysis of data from a cohort of PsA patients. The source population consisted of individuals who enrolled in the Corrona PsA/spondyloarthritis (SpA) registry. This independent, prospective, observational, disease-based registry includes adults (18 years or older) diagnosed by a rheumatologist to have PsA, axial or peripheral SpA, or ankylosing spondylitis. As of December 2017, the registry database included information on 2526 patients recruited at 35 private and academic practice sites in 22 states across the United States, with data from 10767 patient visits and 5928 patient-years of follow-up (median, 3.3 years). Overall objectives of the registry are to understand the epidemiology and natural history of these conditions, including comorbidities, prescribing practices, and comparative effectiveness of treatments, in a real-world setting.

The Corrona PsA/SpA registry was established in accordance with the Declaration of Helsinki. All participating investigators were required to obtain full Institutional Review Board approval for conducting noninterventional research involving human subjects with a limited dataset. Sponsor approval and continuing review were obtained through a central Institutional Review Board (IRB) (New England Independent Review Board, NEIRB No. 120160070). Sponsor approval was first obtained on February 27, 2013. For academic investigative sites that did not receive a waiver to use the central IRB, full board approval was obtained from the respective governing IRBs and documentation of approval was submitted to Corrona prior to initiating any study procedures. Informed consent was obtained from all individual participants included in the study. The study is registered with http://www.clinicaltrials. gov (NCT02530268).

\section{Study eligibility criteria}

This analysis included patients with a diagnosis of PsA who enrolled in the registry between March 21, 2013 (registry initiation), and January 31, 2017, and who received TNFi monotherapy, csDMARD monotherapy, or TNFi/csDMARD combination therapy during this period. The csDMARD category comprised methotrexate, hydroxychloroquine, leflunomide, and sulfasalazine. The TNFi category comprised therapies that were approved for the treatment of PsA before registry initiation (etanercept, adalimumab, infliximab, and golimumab). After the index date (first recorded use) for TNFi and/or csDMARD therapy, patients were required to have at least 6 months of follow-up. Thus, the entire study period was from March 21, 2013, to July 31, 2017. Of 1608 patients in the registry during the study period, $1266 \mathrm{had}$ the necessary follow-up and were included in the analysis.

The Corrona PsA/SpA registry excludes patients with a diagnosis of rheumatoid arthritis, systemic lupus erythematosus, or any other form of autoimmune inflammatory arthritis as well as patients who are participating in or planning to participate in a clinical trial with a nonmarketed or marketed investigational drug (i.e., phase I-IV drug trial). This analysis did not have patient exclusion criteria beyond those of the Corrona PsA/SpA registry.

\section{Data collection}

The Corrona PsA/SpA registry collects data from patients and their treating rheumatologists, including information on disease duration, prognosis, disease severity and activity, medical comorbidities, use of medications (biologics, 
csDMARDs, and prednisone), and adverse events. Follow-up assessments, which are completed during routine clinical encounters, are requested at least as often as every 6 months. Validated tools are used to measure the disease severity and activity. Enthesitis severity is measured with the Spondyloarthritis Research Consortium of Canada (SPARCC) scale for tenderness from 0 to 16 [10]. Dactylitis severity is measured as the number of digits with dactylitis present from 0 to 20 . The percentage of body surface area affected is recorded. Nail psoriasis severity is measured on a visual analog scale from 0 to 100. Physicians measure and record tender joint count from 0 to 68, swollen joint count from 0 to 66 (excluding hips), and Disease Activity Score from 28 joints with C-reactive protein (DAS28-CRP) [11, 12]. Patients complete the Health Assessment Questionnaire modified for Spondyloarthropathies (HAQ-S) with scores from 0 (no difficulty) to 3 (unable to do) [13], global skin assessment and global joint assessment from 0 (no disease activity) to 100 (most disease activity), and a pain visual analog scale from 0 (no pain) to 100 (worst pain). Patient and physician global disease assessments are combined with 28 swollen and tender joint counts to calculate the Clinical Disease Activity Index (CDAI) from 0 to 76, where $<2.9$ is remission, 2.9-10.0 low disease activity, 10.1-22.0 moderate disease activity, and $>22.0$ high disease activity [14]. Disease Activity in Psoriatic Arthritis (DAPSA) scores are calculated from joint counts (68 tender/66 swollen), CRP, and patient assessments of disease activity and pain, yielding scores consistent with remission $(0-4)$ or mild (5-14), moderate (15-28), or high (>28) disease activity [15]. Patients use the Work Productivity and Activity Impairment questionnaire to report the effect of PsA/SpA on work (percentage of hours missed, impairment while at work, and work hours affected) and daily activities [16-18].

\section{Statistical analysis}

For this descriptive analysis, no hypothesis was generated a priori for statistical comparisons between or across the treatment cohorts. Demographics, clinical characteristics, and disease activity at the index date were summarized by index therapy for all PsA patients in the registry who received a TNFi or csDMARD at least once during the study period and had at least 1 follow-up visit at least 6 months after the index date. Treatment patterns were summarized by index therapy for the subset of patients who completed the 12-month study visit between 9 and 15 months postindex (12 \pm 3 months). Each analysis was conducted separately for two categories of treatment- "existing use" starting before registry entry or "initiated use" starting on/after registry entry.

Treatment patterns of interest based on medication use reported in the registry included treatment persistence, discontinuation, switch, and restart (Table 1). Persistence was defined as recorded use of the index therapy for at least 12 months after the index date without any treatment gap of at least 30 days. Discontinuation was defined as any treatment gap of at least 30 days without a subsequent prescription for the index therapy during follow-up. Restarting therapy was defined as a stoppage of index therapy for at least 30 days and restarting the index therapy after the treatment gap, without starting another therapy. Switching was defined as discontinuation of the index therapy and initiation of another therapy during follow-up. Patients with at least 6 months of follow-up postindex but less than 12 months of follow-up after the first use of the index therapy could not be defined as achieving treatment persistence; if they did not discontinue, switch, or restart therapy during this follow-up, they were categorized as having "no change ( $<12$ months)."

The following treatment patterns were also examined (Table 1): stopping therapy was defined as stopping all PsA-related drugs and not receiving any other drug therapy after a gap in therapy of at least 30 days; therapy

Table 1 Treatment pattern definitions

\begin{tabular}{ll}
\hline Treatment pattern & Definition \\
\hline $\begin{array}{l}\text { Persistence } \\
\text { No change for }<12 \text { months }\end{array}$ & Continuous use for at least 12 months without a treatment gap of at least 30 days \\
$\begin{array}{l}\text { Discontinuation } \\
\text { Restart }\end{array}$ & A treatment gap of at least 30 days, with no subsequent use of the index medication \\
A treatment gap of at least 30 days, then restarted the same therapy after the gap (without discontinuation or \\
therapy switch/add-on) \\
Stop & A treatment gap of at least 30 days, with no subsequent use of any PsA medication during follow-up \\
Add-on & Discontinuation of index medication, then initiation of another medication \\
Reduction & Continuation of index medication with initiation of another medication \\
& Discontinuation of either TNFi or csDMARD, with continuation of the other index medication (i.e., switch \\
from combination to monotherapy)
\end{tabular}

CSDMARD conventional synthetic disease-modifying antirheumatic drug, PsA psoriatic arthritis, TNFi tumor necrosis factor inhibitor 
add-on (in the TNFi monotherapy or csDMARD monotherapy cohorts) was defined as the initiation of additional medication(s) along with continuation of index medication; reduction in therapy (in the combination therapy cohort) was defined as the discontinuation of a biologic or nonbiologic and continuing TNFi monotherapy or csDMARD monotherapy; and dose stretching included patients who received a Food and Drug Administration (FDA)-approved dose of a TNFi at the index date, and less than the FDA-approved dose of that TNFi during follow-up.

\section{Results}

\section{Existing therapy: patient characteristics at the index date}

At registry entry, 1144 patients with existing therapy received treatment as TNFi monotherapy $(n=421)$, csDMARD monotherapy $(n=347)$, or combination therapy $(n=376)$, of whom 690 were evaluable at 12 months. In the analysis of demographics and clinical characteristics by existing index therapy, the mean age at the index date was 57.7 years for csDMARD monotherapy and 51.9-53.9 years in the other groups (Table 2). Women comprised $59 \%$ of patients receiving existing TNFi monotherapy and $46-50 \%$ of patients in the other groups. Prior csDMARD use was reported for $46 \%$ of patients in the existing TNFi monotherapy group and $98-100 \%$ of patients in the other groups.

In the analysis of PsA disease activity and severity at the index date by existing index therapy, the mean scores for disability, work impairment, enthesitis, dactylitis, body surface area, and nail psoriasis were generally consistent with low disease activity, and those for CDAI and DAPSA were consistent with low or moderate disease activity (Table 2). At the index date, peripheral involvement was reported for $77-87 \%$ of patients and axial involvement for $7-14 \%$. The mean score for DAS28-CRP was 2.8 in the TNFi monotherapy group and 3.1 in each of the other groups. The mean CDAI scores for TNFi monotherapy, csDMARD monotherapy, and combination therapy were 9.7, 11.6, and 11.7, respectively, and the mean DAPSA scores were 13.9, 17.2, and 16.5, respectively. The mean scores for disability and work impairment were low among existing therapy patients, with the mean HAQ-S scores ranging from 0.2 to 0.3 and percentage of work hours affected overall ranging from 15 to $18 \%$. The mean duration of PsA was 10.5 years in the csDMARD monotherapy group and 13.0 years each in the TNFi monotherapy and combination therapy groups.

\section{Existing therapy: treatment patterns postindex}

Of 1144 patients with existing therapy, $690(60 \%)$ patients were evaluable for treatment patterns because they had a 12-month follow-up visit between 9 and 15 months postindex for existing TNFi monotherapy $(n=251)$, csDMARD monotherapy $(n=225)$, or combination therapy $(n=214)$. Most patients with existing TNFi monotherapy, csDMARD monotherapy, or combination therapy achieved either treatment persistence for at least 12 months $(93,87$, and $87 \%$, respectively) or no change in therapy with less than 12 months of follow-up after first use $(6,5$, and $5 \%$, respectively; Table 3). The postindex treatment patterns of discontinuation of index therapy, switching to another biologic, and restarting therapy after an interruption each occurred in less than 5\% of patients in each group, apart from discontinuation of combination therapy in $8 \%$ of patients. TNFi dose stretching was reported for $10(4 \%)$ patients in the TNFi monotherapy group and $3(1 \%)$ patients in the combination therapy group.

\section{Initiated therapy: patient characteristics at the index date}

Initiation of therapy starting on or after registry enrollment was reported for 122 patients who initiated TNFi monotherapy ( $n=43)$, csDMARD monotherapy $(n=56)$, or combination therapy $(n=23)$, of whom 76 were evaluable at 12 months. In the analysis of demographics and clinical characteristics by initiated index therapy (Table 4), the mean age at the index date was 55.8 years for csDMARD monotherapy and 50.7-52.3 years in the other groups. Women comprised $43-48 \%$ of patients receiving initiated therapy. History of csDMARD use was reported for $30 \%$ of patients in the initiated TNFi monotherapy group, $0 \%$ in the initiated csDMARD monotherapy group, and $57 \%$ in the combination therapy group.

In the analysis of PsA disease activity and severity at the index date by initiated index therapy, the mean scores for CDAI, DAPSA, disability, work impairment, enthesitis, dactylitis, body surface area, and nail psoriasis were consistent with low or moderate disease activity (Table 4). At the index date, peripheral involvement was reported for $78-91 \%$ of patients and axial involvement for $5-13 \%$. The mean DAS28-CRP scores for TNFi monotherapy, csDMARD monotherapy, and combination therapy were 3.4, 3.8 , and 2.9, respectively. The mean CDAI scores for TNFi monotherapy, csDMARD monotherapy, and combination therapy were $12.7,16.2$, and 12.2 , respectively, and the mean DAPSA scores were 19.2, 24.7, and 19.1, respectively. The mean HAQ-S scores ranged from 0.3 to 0.4 , and the percentage of work hours affected overall ranged from 19 to $29 \%$. 
Table 2 Existing therapy: patient characteristics at the index date

\begin{tabular}{|c|c|c|c|}
\hline Patient characteristic & TNFi $(n=421)$ & $\operatorname{csDMARD}(n=347)$ & Combination $(n=376)$ \\
\hline Age, years & $51.9 \pm 12.3$ & $57.7 \pm 13.3$ & $53.9 \pm 11.3$ \\
\hline Sex, female & $244(59)$ & $158(46)$ & $185(50)$ \\
\hline Race, White & $386(92)$ & $326(94)$ & $327(87)$ \\
\hline Currently employed & $275(65)$ & $188(54)$ & $222(59)$ \\
\hline \multicolumn{4}{|l|}{ Body mass index } \\
\hline Normal/underweight & $53(13)$ & $62(18)$ & $65(17)$ \\
\hline Overweight & $144(34)$ & $92(27)$ & $96(26)$ \\
\hline Obese & $202(48)$ & $182(52)$ & $204(54)$ \\
\hline Concurrent psoriasis & $366(87)$ & $300(86)$ & $312(83)$ \\
\hline Axial involvement & $59(14)$ & $26(7)$ & $33(9)$ \\
\hline Peripheral involvement & $324(77)$ & $302(87)$ & $312(83)$ \\
\hline \multicolumn{4}{|l|}{ History of comorbidities } \\
\hline Cardiovascular & $217(52)$ & $189(54)$ & $190(51)$ \\
\hline Malignancy & $33(8)$ & $30(9)$ & $26(7)$ \\
\hline Diabetes & $58(14)$ & $56(16)$ & $55(15)$ \\
\hline Serious infection & $16(4)$ & $22(6)$ & $20(5)$ \\
\hline History of nonTNFi biologic use $\mathrm{u}^{\mathrm{a}}$ & $4(1)$ & $0(0)$ & $3(1)$ \\
\hline History of csDMARD use & $192(46)$ & $347(100)$ & $369(98)$ \\
\hline Methotrexate & $175(42)$ & $313(90)$ & $349(93)$ \\
\hline Other csDMARD ${ }^{\mathrm{b}}$ & $53(13)$ & $73(21)$ & $72(19)$ \\
\hline Current prednisone use & $13(3)$ & $30(9)$ & $20(5)$ \\
\hline Duration of PsA, years & $13.0 \pm 9.9$ & $10.5 \pm 10.2$ & $13.0 \pm 10.1$ \\
\hline Enthesitis & $74(18)$ & $52(15)$ & $75(20)$ \\
\hline SPARCC enthesitis $\left(1^{\mathrm{c}}-16\right)$ & $4.3 \pm 3.5$ & $4.4 \pm 3.2$ & $4.1 \pm 2.8$ \\
\hline Dactylitis & $27(6)$ & $25(7)$ & $12(3)$ \\
\hline Dactylitis count $\left(1^{\mathrm{c}}-20\right)$ & $1.7 \pm 1.4$ & $1.9 \pm 1.2$ & $2.1 \pm 1.4$ \\
\hline Body surface area, $\%$ & $4.9 \pm 8.7$ & $4.8 \pm 9.3$ & $5.0 \pm 11.9$ \\
\hline Body surface area $>3 \%$ & $121(30)$ & $100(31)$ & $94(26)$ \\
\hline Nail psoriasis $(0-100)$ & $5.6 \pm 12.4$ & $8.1 \pm 22.6$ & $7.2 \pm 14.3$ \\
\hline DAS28-CRP (2-10) & $2.8 \pm 1.0$ & $3.1 \pm 1.0$ & $3.1 \pm 1.0$ \\
\hline Tender joint count $(0-68)$ & $3.3 \pm 7.4$ & $4.0 \pm 8.4$ & $4.5 \pm 9.4$ \\
\hline Swollen joint count, excluding hips (0-66) & $1.3 \pm 2.9$ & $2.2 \pm 4.7$ & $1.7 \pm 3.3$ \\
\hline Physician global assessment (0-100) & $12.0 \pm 15.5$ & $15.5 \pm 17.4$ & $15.3 \pm 17.4$ \\
\hline Patient global joint assessment $(0-100)$ & $41.7 \pm 32.3$ & $42.7 \pm 30.8$ & $43.3 \pm 31.2$ \\
\hline Patient global skin assessment $(0-100)$ & $40.6 \pm 32.0$ & $40.9 \pm 30.2$ & $42.2 \pm 31.0$ \\
\hline Patient-reported pain $(0-100)$ & $31.6 \pm 28.5$ & $36.2 \pm 29.1$ & $34.8 \pm 27.8$ \\
\hline Clinical disease activity index (0-76) & $9.7 \pm 6.6$ & $11.6 \pm 9.2$ & $11.7 \pm 8.4$ \\
\hline DAPSA (0-164) & $13.9 \pm 12.8$ & $17.2 \pm 16.7$ & $16.5 \pm 15.4$ \\
\hline HAQ-S (0-3) & $0.2 \pm 0.4$ & $0.3 \pm 0.4$ & $0.3 \pm 0.4$ \\
\hline \multicolumn{4}{|l|}{ Work productivity and activity impairment } \\
\hline Work hours missed, $\%^{\mathrm{d}}$ & $3.5 \pm 13.4$ & $1.3 \pm 8.6$ & $2.7 \pm 10.5$ \\
\hline Impairment while working, $\%^{\mathrm{d}}$ & $13.8 \pm 20.3$ & $14.6 \pm 18.9$ & $15.4 \pm 19.8$ \\
\hline Work hours affected overall, $\%{ }^{\mathrm{d}}$ & $15.2 \pm 21.7$ & $14.9 \pm 18.6$ & $17.5 \pm 22.4$ \\
\hline Daily activities impaired, $\%^{\mathrm{d}}$ & $16.3 \pm 22.3$ & $17.8 \pm 21.9$ & $19.3 \pm 22.8$ \\
\hline
\end{tabular}

Results are shown as mean \pm standard deviation or number of patients $(\%)$

csDMARD conventional synthetic disease-modifying antirheumatic drug, DAPSA Disease Activity in Psoriatic Arthritis, DAS28-CRP Disease Activity Score from 28 joints with C-reactive protein, $H A Q-S$ Health Assessment Questionnaire modified for spondyloarthropathies, PsA psoriatic arthritis, SPARCC Spondyloarthritis Research Consortium of Canada, TNFi tumor necrosis factor inhibitor

${ }^{a}$ Abatacept, tocilizumab, anakinra, rituximab, secukinumab, tofacitinib, or ustekinumab

${ }^{\mathrm{b}}$ Hydroxychloroquine, leflunomide, or sulfasalazine

${ }^{\mathrm{c}}$ Patients with no enthesitis/dactylitis (values of 0 ) were not included in calculations of mean counts

${ }^{\mathrm{d}}$ Patients rated percentage of impairment specifically related to PsA or spondyloarthritis 
Table 3 Existing therapy: postindex treatment patterns

\begin{tabular}{|c|c|c|c|}
\hline Treatment pattern & TNFi $(n=251)$ & csDMARD $(n=225)$ & Combination $(n=214)$ \\
\hline Persistence $\geq 12$ months & $233(92.8)$ & $196(87.1)$ & $186(86.9)$ \\
\hline Total time on drug, months & $68.6 \pm 46.4$ & $82.5 \pm 78.1$ & $49.8 \pm 37.7$ \\
\hline Time after index, months & $11.9 \pm 2.0$ & $11.8 \pm 2.2$ & $11.7 \pm 2.4$ \\
\hline Dose stretching & $10(4.0)$ & $0(0.0)$ & $3(1.4)$ \\
\hline No change for $<12$ months & $14(5.6)$ & $11(4.9)$ & $11(5.1)$ \\
\hline Change in therapy & $4(1.6)$ & $18(8.0)$ & $17(7.9)$ \\
\hline Discontinuation & $3(1.2)$ & $8(3.6)$ & $17(7.9)$ \\
\hline Time on drug, months & $8.9 \pm 1.8$ & $8.3 \pm 1.9$ & $8.5 \pm 2.3$ \\
\hline \multicolumn{4}{|l|}{ Switch } \\
\hline To another biologic & $2(0.8)$ & $2(0.9)$ & $4(1.9)$ \\
\hline To methotrexate & $0(0.0)$ & $1(0.4)$ & - \\
\hline \multicolumn{4}{|l|}{ Add-on } \\
\hline Added another biologic & $0(0.0)$ & $7(3.1)$ & - \\
\hline Added methotrexate & $2(0.8)$ & $1(0.4)$ & - \\
\hline \multicolumn{4}{|l|}{ Reduction } \\
\hline Dropped biologic & - & - & $3(1.4)$ \\
\hline Dropped methotrexate & - & - & $8(3.7)$ \\
\hline Stopped & $0(0.0)$ & $1(0.4)$ & $5(2.3)$ \\
\hline Restarted & $0(0.0)$ & $3(1.3)$ & $1(0.5)$ \\
\hline Time to restart, months & - & $7.5 \pm 0.2$ & $0.0 \pm 0.0$ \\
\hline
\end{tabular}

Results are shown as mean \pm standard deviation or number of patients $(\%)$

csDMARD conventional synthetic disease-modifying antirheumatic drug, TNFi tumor necrosis factor inhibitor
The mean duration of PsA was 5.7 years in the csDMARD monotherapy group and 10.1-10.2 years in the other groups.

\section{Initiated therapy: treatment patterns postindex}

Of the 122 patients who initiated therapy, $76(62 \%)$ were evaluable for treatment patterns because they had a 12-month follow-up visit between 9 and 15 months postindex for initiated TNFi monotherapy $(n=26)$, csDMARD monotherapy $(n=35)$, or combination therapy $(n=15)$. Among the patients with initiated TNFi monotherapy, csDMARD monotherapy, or combination therapy, approximately half achieved treatment persistence for at least 12 months (50, 43 , and $53 \%$, respectively), and $20 \%$ or more had no change in the index therapy during less than 12 months of followup after first use $(27,20$, and $20 \%$, respectively; Table 5). In the initiated TNFi monotherapy, csDMARD monotherapy, and combination therapy groups, the discontinuation of index therapy was reported for 19,26 , and $27 \%$ of patients, respectively, and switching to another biologic (or from a csDMARD to a biologic) for 4,11 , and $13 \%$ of patients, respectively; restarting therapy after an interruption of at least 30 days was not reported for any patient (Table 5). TNFi dose stretching was not reported for any patient with initiated therapy.

\section{Discussion}

In this real-world study of PsA patients, most of the reported use of TNFi monotherapy, csDMARD monotherapy, or TNFi/csDMARD combination therapy was existing when the patient enrolled in the Corrona PsA/SpA registry. Although the retrospective analysis was neither designed nor powered for comparisons across groups, a few apparent differences were noted. Compared to patients with existing TNFi monotherapy, patients with existing csDMARD monotherapy at registry enrollment were 6 years older, were less likely to be female, and had a PsA duration that was 2.5 years shorter. Other demographics, clinical characteristics, and disease activity were similar across the groups for existing therapy at the index date. Across the treatment groups, patients with existing therapy had DAS28-CRP scores that were mostly consistent with remission or low disease activity as well as low scores at the index date (i.e., registry entry for existing therapy) for several measures of disease activity, disability, or work impairment. The mean scores for DAPSA, a composite measure that includes each of the key components of PsA [15], were near the cutoff between mild and moderate disease activity. These results suggest that PsA was stable among patients who were already being treated with TNFi or csDMARD therapy when they entered the registry. However, the registry was 
Table 4 Initiated therapy: patient characteristics at the index date

\begin{tabular}{|c|c|c|c|}
\hline Patient characteristic & TNFi $(n=43)$ & $\operatorname{csDMARD}(n=56)$ & Combination $(n=23)$ \\
\hline Age, years & $50.7 \pm 14.0$ & $55.8 \pm 14.1$ & $52.3 \pm 13.5$ \\
\hline Sex, female & $19(44)$ & $24(43)$ & $11(48)$ \\
\hline Race, White & $40(91)$ & $51(91)$ & $23(100)$ \\
\hline Currently employed & $29(66)$ & $28(50)$ & $14(61)$ \\
\hline \multicolumn{4}{|l|}{ Body mass index } \\
\hline Normal/underweight & $9(21)$ & $4(7)$ & $1(4)$ \\
\hline Overweight & $14(33)$ & $12(21)$ & $8(35)$ \\
\hline Obese & $18(40)$ & $37(66)$ & $8(35)$ \\
\hline Concurrent psoriasis & $38(88)$ & $49(88)$ & $15(65)$ \\
\hline Axial involvement & $4(9)$ & $3(5)$ & $3(13)$ \\
\hline Peripheral involvement & $39(91)$ & $50(89)$ & $18(78)$ \\
\hline \multicolumn{4}{|l|}{ History of comorbidities } \\
\hline Cardiovascular & $13(30)$ & $28(50)$ & $9(39)$ \\
\hline Malignancy & $5(11)$ & $2(4)$ & $2(9)$ \\
\hline Diabetes & $7(16)$ & $6(11)$ & $1(4)$ \\
\hline Serious infection & $2(5)$ & $3(5)$ & $1(4)$ \\
\hline History of nonTNFi biologic use ${ }^{a}$ & $2(5)$ & $0(0)$ & $0(0)$ \\
\hline History of csDMARD use & $13(30)$ & $0(0)$ & $13(57)$ \\
\hline Methotrexate & $10(23)$ & $0(0)$ & $11(48)$ \\
\hline Other csDMARD ${ }^{\mathrm{b}}$ & $4(9)$ & $0(0)$ & $3(13)$ \\
\hline Current prednisone use & $1(2)$ & $4(7)$ & $2(9)$ \\
\hline Duration of PsA, years & $10.2 \pm 10.5$ & $5.7 \pm 6.7$ & $10.1 \pm 7.8$ \\
\hline Enthesitis & $14(32)$ & $8(14)$ & $3(13)$ \\
\hline SPARCC enthesitis $\left(1^{c}-16\right)$ & $3.1 \pm 3.0$ & $4.0 \pm 3.5$ & $1.7 \pm 0.6$ \\
\hline Dactylitis & $7(16)$ & $14(25)$ & $4(17)$ \\
\hline Dactylitis count $\left(1^{\mathrm{c}}-20\right)$ & $1.1 \pm 0.4$ & $2.1 \pm 0.8$ & $2.8 \pm 2.2$ \\
\hline Body surface area, $\%$ & $6.2 \pm 8.8$ & $5.4 \pm 8.9$ & $1.3 \pm 2.1$ \\
\hline Body surface area $>3 \%$ & $18(41)$ & $20(38)$ & $4(18)$ \\
\hline Nail psoriasis $(0-100)$ & $11.9 \pm 18.8$ & $5.9 \pm 15.2$ & $10.3 \pm 23.3$ \\
\hline DAS28-CRP (2-10) & $3.4 \pm 0.7$ & $3.8 \pm 0.8$ & $2.9 \pm 1.0$ \\
\hline Tender joint count $(0-68)$ & $3.5 \pm 5.0$ & $5.3 \pm 6.6$ & $4.6 \pm 6.9$ \\
\hline Swollen joint count, excluding hips (0-66) & $2.1 \pm 2.8$ & $4.2 \pm 5.1$ & $2.9 \pm 4.8$ \\
\hline Physician global assessment (0-100) & $26.1 \pm 22.2$ & $24.3 \pm 19.1$ & $24.4 \pm 23.3$ \\
\hline Patient global joint assessment $(0-100)$ & $37.0 \pm 30.0$ & $39.0 \pm 24.4$ & $50.0 \pm 32.9$ \\
\hline Patient global skin assessment $(0-100)$ & $39.2 \pm 29.2$ & $42.4 \pm 24.2$ & $48.6 \pm 30.5$ \\
\hline Patient-reported pain $(0-100)$ & $38.9 \pm 30.0$ & $49.1 \pm 27.2$ & $37.0 \pm 31.3$ \\
\hline Clinical disease activity index (0-76) & $12.7 \pm 7.4$ & $16.2 \pm 8.5$ & $12.2 \pm 9.1$ \\
\hline DAPSA $(0-164)$ & $19.2 \pm 13.3$ & $24.7 \pm 17.1$ & $19.1 \pm 28.4$ \\
\hline HAQ-S (0-3) & $0.3 \pm 0.4$ & $0.3 \pm 0.3$ & $0.4 \pm 0.6$ \\
\hline \multicolumn{4}{|l|}{ Work productivity and activity impairment } \\
\hline Work hours missed, $\%^{\mathrm{d}}$ & $3.0 \pm 7.6$ & $10.2 \pm 28.7$ & $1.7 \pm 5.8$ \\
\hline Impairment while working, $\%^{\mathrm{d}}$ & $16.7 \pm 21.2$ & $23.9 \pm 17.1$ & $17.7 \pm 19.8$ \\
\hline Work hours affected overall, $\%$ d & $20.1 \pm 24.1$ & $28.5 \pm 24.5$ & $19.2 \pm 20.6$ \\
\hline Daily activities impaired, $\%^{\mathrm{d}}$ & $25.7 \pm 27.2$ & $30.4 \pm 25.6$ & $26.4 \pm 25.6$ \\
\hline
\end{tabular}

Results are shown as mean \pm standard deviation or number of patients (\%)

csDMARD conventional synthetic disease-modifying antirheumatic drug, DAPSA Disease Activity in Psoriatic Arthritis, DAS28-CRP Disease Activity Score from 28 joints with C-reactive protein, HAQ-S Health Assessment Questionnaire modified for spondyloarthropathies, PSA psoriatic arthritis, SPARCC Spondyloarthritis Research Consortium of Canada, TNFi tumor necrosis factor inhibitor

${ }^{a}$ Abatacept, tocilizumab, anakinra, rituximab, secukinumab, tofacitinib, or ustekinumab

${ }^{b}$ Hydroxychloroquine, leflunomide, or sulfasalazine

${ }^{c}$ Patients with no enthesitis/dactylitis (values of 0 ) were not included in calculations of mean counts

${ }^{\mathrm{d}}$ Patients rated percentage of impairment specifically related to PsA or spondyloarthritis 
Table 5 Initiated therapy: postindex treatment patterns

\begin{tabular}{llll}
\hline Treatment pattern & TNFi $(n=26)$ & csDMARD $(n=35)$ & Combination $(n=15)$ \\
\hline Persistence $\geq 12$ months & $13(50.0)$ & $15(42.9)$ & $8(53.3)$ \\
Total time on drug, months & $15.9 \pm 5.4$ & $16.9 \pm 8.7$ & $16.0 \pm 5.0$ \\
Time after index, months & $13.3 \pm 1.2$ & $13.3 \pm 1.5$ & $13.3 \pm 0.9$ \\
Dose stretching & $0(0.0)$ & $0(0.0)$ & $0(0.0)$ \\
No change for $<12$ months & $7(26.9)$ & $7(20.0)$ & $3(20.0)$ \\
Change in therapy & $6(23.1)$ & $13(37.1)$ & $4(26.7)$ \\
Discontinuation & $5(19.2)$ & $9(25.7)$ & $4(26.7)$ \\
Time on drug, months & $9.2 \pm 2.4$ & $8.0 \pm 2.1$ & $7.5 \pm 0.7$ \\
Switch & & & $2(13.3)$ \\
To another biologic & $1(3.8)$ & $4(11.4)$ & - \\
To methotrexate & $0(0.0)$ & $0(0.0)$ & - \\
Add-on & & & - \\
Added another biologic & $0(0.0)$ & $4(11.4)$ & \\
Added methotrexate & $1(3.8)$ & $0(0.0)$ & $0(0.0)$ \\
Reduction & & - & $3(20.0)$ \\
Dropped biologic & - & - & $0(0.0)$ \\
Dropped methotrexate & - & $5(14.3)$ & $0(0.0)$ \\
Stopped & $2(7.7)$ & $0(0.0)$ & - \\
Restarted & - & - & \\
Time to restart, months & $-0.0)$ & & \\
\hline
\end{tabular}

Results are shown as mean \pm standard deviation or number of patients $(\%)$

csDMARD conventional synthetic disease-modifying antirheumatic drug, TNFi tumor necrosis factor inhibitor not designed to determine how many patients required dose escalation to achieve stable disease control before registry entry or how long those dose adjustments were required.

In the examination of postindex treatment patterns among patients with existing therapy who completed a 12-month follow-up visit between 9 and 15 months postindex (12 \pm 3 months), almost all were persistent on that therapy. Most patients (87-93\% in each existing therapy group) satisfied the study definition of treatment persistence for at least 12 months. Another 5-6\% of patients in each group had no change in index therapy but less than 12 months of followup after first use. Only $2 \%$ of patients with existing TNFi monotherapy and $8 \%$ with existing csDMARD monotherapy or combination therapy had any change in therapy postindex. Treatment patterns were generally similar between patients with existing monotherapy or existing combination therapy, suggesting that the concomitant use of a csDMARD and TNFi did not influence treatment persistence for either existing therapy.

Patient characteristics and treatment patterns were analyzed separately for patients who initiated therapy with a TNFi or csDMARD after enrolling in the registry. Despite comprising less than $10 \%$ of the study population, this cohort had several notable characteristics. Prior csDMARD use was reported for $30-57 \%$ of patients who initiated therapy (compared with $46-100 \%$ of patients with existing therapy).
Compared with patients with existing therapy, those who initiated therapy appeared to have higher disease activity, more dactylitis, and more work impairment at the index date. Each of these findings is consistent with stable disease management in the patients with existing therapy versus the patients who needed to start new therapy. Patients who initiated therapy also had a shorter duration of PsA than the patients with existing therapy. For both initiated and existing therapy, csDMARD monotherapy was started 3.5-4.5 years sooner than either TNFi monotherapy or TNFi/csDMARD combination therapy in the treatment course for PsA. Earlier use of csDMARDs than TNFi was supported by older treatment guidelines for PsA [19], whereas more recent treatment guidelines for PsA support the use of TNFi therapy early in the treatment pathway [2,3]. In this analysis of real-world treatment of PsA patients between 2013 and 2017, more than half of the initiated therapy was either TNFi monotherapy or TNFi/csDMARD combination therapy, and few of these patients had prior treatment for PsA, suggesting that many PsA patients now start treatment with a regimen that includes a TNFi.

In the examination of postindex treatment patterns for initiated therapy, approximately $30 \%$ of patients changed index therapy by the 12-month follow-up visit. These patients typically discontinued the index therapy without restarting it. Persistence results for initiated therapy in this analysis 
are consistent with numerous previous analyses reporting that PsA patients often discontinue therapy in the first 12-24 months [20-43]. Our results extend those findings by showing that once PsA patients were on established TNFi/ csDMARD therapy (existing use) and in a state of remission/low disease activity, they were highly likely to continue on that therapy without changes. Thus, the observed discrepancies in treatment persistence between initiated and existing use suggest that patients required a change in initiated therapy because they did not respond to it or did not tolerate it well. Confounding by indication was possible; disease severity was generally mild in all cohorts and was within the same range across existing and initiated therapy, but some differences were seen for prior csDMARD use. Previous registry studies provided similar results but were conducted either outside the United States [25-39] or they used a subset of PsA patients from a registry in the United States that was designed primarily for patients with rheumatoid arthritis [40-43]. Our study used data from a registry in the United States that was specifically designed to collect information about patients with PsA. A systematic review of the previous registries was beyond the scope of this work, but results from previous registries (see APPENDIX) may provide insight into areas for future research as the data collected from the Corrona PsA/SpA registry mature. Those analyses could include explorations of longer term treatment patterns, predictors for treatment persistence, and clinical outcomes after treatment persistence or treatment discontinuation in PsA patients.

The TNFi category for this analysis included etanercept, adalimumab, infliximab, and golimumab, but it did not include biologics that were approved for the treatment of PsA after the study period began, including the TNFi certolizumab and the nonTNFi biologics ustekinumab, secukinumab, ixekizumab, and abatacept. It also excluded biologics that were approved for use in other conditions but not in PsA at the start of the study period. Additional analyses would be needed to determine whether other biologics have treatment patterns and persistence rates that are similar to those for established TNFi therapies. The study examined decreased usage through either therapy discontinuation or restarting after a treatment gap but did not examine increased usage through dose escalation, which previous studies reported for more than half of the PsA patients who received TNFi therapy [31, 44-48]. Another potential limitation of this analysis was the small number of patients with initiated use, who comprised less than $10 \%$ of the study population. As a result, a few patients with changes in therapy during follow-up had a substantial effect on treatment persistence rates for initiated use. This analysis included data from centers across the United States, but it is unknown whether the results are generalizable to other countries. This analysis did not examine treatment outcomes.
The results of this analysis of real-world treatment patterns in a PsA patient registry suggest that nonpersistence for TNFi monotherapy, csDMARD monotherapy, or TNFi/ csDMARD combination therapy occurs more commonly for newly initiated therapy than for existing therapy. After stabilization of TNFi or csDMARD therapy in PsA patients, treatment persistence for 12 months or more is common. In this analysis of patients with PsA in a nationwide registry study, TNFi monotherapy or TNFi/csDMARD combination therapy was initiated several years later than csDMARD monotherapy. New treatment guidelines for PsA support the use of TNFi monotherapy or combination therapy early in the treatment course. Additional research is needed to examine whether PsA patients receive TNFi earlier as new treatment guidelines are disseminated and implemented in clinical practice.

Previous abstract publication: Mease P, Accortt N, Rebello S, et al. Persistence of monotherapy or combination therapy with disease-modifying agents in patients with psoriatic arthritis in a real-world setting [abstract FRI0136]. Ann Rheum Dis 2018;77:612. https://doi.org/10.1136/annrh eumdis-2018-eular.1929.

The principal investigator, Philip J. Mease, takes full responsibility for the correctness and integrity of the data.

Acknowledgements Jonathan Latham of PharmaScribe, LLC (with support from Amgen Inc.), and Linda Rice of Amgen Inc. provided medical writing assistance.

Author contributions All authors contributed to the design of the work, interpretation of the data, and critical revisions to the content. SR, CJE, and RWH provided a study report that was the basis for the draft of the work. PJM and JDG contributed to data collection. CJE and RWH analyzed the data. All authors approved the work for publication and agree to be accountable for all aspects of the work. NAA, SR, CJE, RWH, GAA, MMFG, JDG, and DHC are current or former employees of the study sponsor or the study funder.

Funding This study was sponsored by Corrona, LLC and funded by Amgen Inc. Corrona has been supported through contracted subscriptions in the last 2 years by AbbVie, Amgen Inc., Boehringer Ingelheim, Bristol-Myers Squibb, Celgene, Crescendo, Eli Lilly and Company, Genentech, Gilead, GlaxoSmithKline, Janssen, Merck, Momenta Pharmaceuticals, Novartis, Ortho Dermatologics (Bausch Health), Pfizer Inc., Regeneron, Roche, Sun, and UCB.

\section{Compliance with ethical standards}

Conflict of interest PJM has received research grants from AbbVie, Amgen Inc., Bristol-Myers Squibb, Celgene, Janssen, Eli Lilly, Novartis, Pfizer, Sun Pharmaceutical Industries Ltd., and UCB; has been a consultant for AbbVie, Amgen Inc., Bristol-Myers Squibb, Celgene, Galapagos, Janssen, Eli Lilly, Merck, Novartis, Pfizer, Sun Pharmaceutical Industries Ltd., UCB, and Zynerba; and has been a speaker for AbbVie, Amgen Inc., Bristol-Myers Squibb, Celgene, Genentech, Janssen, Novartis, Pfizer, and UCB. NAA and DHC are employees and stockholders of Amgen Inc. SR, CJE, RWH, and JDG are employees of Corrona, LLC. CJE is a stockholder of Corrona, LLC, and a mem- 
ber of an advisory board for Merck. JDG is a stockholder of Corrona, LLC, and has been a consultant to Genentech, Janssen, Pfizer, Eli Lilly, and Novartis. GAA and MMFG were stockholders of Amgen Inc. and employees of Amgen Inc. when the work was conducted. Corrona has been supported through contracted subscriptions in the last 2 years by AbbVie, Amgen Inc., Boehringer Ingelheim, Bristol-Myers Squibb, Celgene, Crescendo, Eli Lilly and Company, Genentech, Gilead, GlaxoSmithKline, Janssen, Merck, Momenta Pharmaceuticals, Novartis, Ortho Dermatologics (Bausch Health), Pfizer Inc., Regeneron, Roche, Sun, and UCB.

Ethical approval All procedures performed in studies involving human participants were in accordance with the ethical standards of the institutional research committee and with the 1964 Helsinki declaration and its later amendments.

Data sharing The Corrona dataset is based on a large US multicenter study adhering to a number of institutional review boards, with complex logistics. Patients did not provide consent to raw data sharing during the data collection for this purpose, and the Corrona data sharing policies do not permit raw data sharing for this purpose. An aggregated limited dataset from the current analyses is available to qualified investigators with an approved protocol. Data requests may be sent to Corrona, represented by Dr. Jeffrey D. Greenberg MD MPH, NYU School of Medicine, New York, NY, e-mail jgreenberg@corrona.org.

Open Access This article is distributed under the terms of the Creative Commons Attribution 4.0 International License (http://creativeco mmons.org/licenses/by/4.0/), which permits unrestricted use, distribution, and reproduction in any medium, provided you give appropriate credit to the original author(s) and the source, provide a link to the Creative Commons license, and indicate if changes were made.

\section{References}

1. Veale DJ (2013) Psoriatic arthritis: recent progress in pathophysiology and drug development. Arthritis Res Ther 15(6):224. https ://doi.org/10.1186/ar4414

2. Gossec L, Smolen JS, Ramiro S, de Wit M, Cutolo M, Dougados M, Emery P, Landewe R, Oliver S, Aletaha D, Betteridge N, Braun J, Burmester G, Canete JD, Damjanov N, FitzGerald O, Haglund E, Helliwell P, Kvien TK, Lories R, Luger T, Maccarone M, Marzo-Ortega H, McGonagle D, McInnes IB, Olivieri I, Pavelka K, Schett G, Sieper J, van den Bosch F, Veale DJ, Wollenhaupt J, Zink A, van der Heijde D (2016) European League Against Rheumatism (EULAR) recommendations for the management of psoriatic arthritis with pharmacological therapies: 2015 update. Ann Rheum Dis 75(3):499-510. https://doi.org/10.1136/ annrheumdis-2015-208337

3. Coates LC, Kavanaugh A, Mease PJ, Soriano ER, Laura AcostaFelquer M, Armstrong AW, Bautista-Molano W, Boehncke WH, Campbell W, Cauli A, Espinoza LR, FitzGerald O, Gladman DD, Gottlieb A, Helliwell PS, Husni ME, Love TJ, Lubrano E, McHugh N, Nash P, Ogdie A, Orbai AM, Parkinson A, O'Sullivan D, Rosen CF, Schwartzman S, Siegel EL, Toloza S, Tuong W, Ritchlin CT (2016) Group for research and assessment of psoriasis and psoriatic arthritis 2015 treatment recommendations for psoriatic arthritis. Arthritis Rheumatol 68(5):1060-1071. https:// doi.org/10.1002/art.39573

4. Mease PJ, Goffe BS, Metz J, VanderStoep A, Finck B, Burge DJ (2000) Etanercept in the treatment of psoriatic arthritis and psoriasis: a randomised trial. Lancet 356(9227):385-390. https:// doi.org/10.1016/S0140-6736(00)02530-7

5. Mease PJ, Kivitz AJ, Burch FX, Siegel EL, Cohen SB, Ory P, Salonen D, Rubenstein J, Sharp JT, Tsuji W (2004) Etanercept treatment of psoriatic arthritis: safety, efficacy, and effect on disease progression. Arthritis Rheum 50(7):2264-2272. https://doi. org/10.1002/art.20335

6. Antoni C, Krueger GG, de Vlam K, Birbara C, Beutler A, Guzzo C, Zhou B, Dooley LT, Kavanaugh A (2005) Infliximab improves signs and symptoms of psoriatic arthritis: results of the IMPACT 2 trial. Ann Rheum Dis 64(8):1150-1157. https://doi.org/10.1136/ ard.2004.032268

7. Kavanaugh A, McInnes I, Mease P, Krueger GG, Gladman D, Gomez-Reino J, Papp K, Zrubek J, Mudivarthy S, Mack M, Visvanathan S, Beutler A (2009) Golimumab, a new human tumor necrosis factor $\alpha$ antibody, administered every 4 weeks as a subcutaneous injection in psoriatic arthritis: twenty-four-week efficacy and safety results of a randomized, placebo-controlled study. Arthritis Rheum 60(4):976-986. https://doi.org/10.1002/art.24403

8. Mease PJ, Gladman DD, Ritchlin CT, Ruderman EM, Steinfeld SD, Choy EH, Sharp JT, Ory PA, Perdok RJ, Weinberg MA (2005) Adalimumab for the treatment of patients with moderately to severely active psoriatic arthritis: results of a doubleblind, randomized, placebo-controlled trial. Arthritis Rheum 52(10):3279-3289. https://doi.org/10.1002/art.21306

9. Mease PJ, Fleischmann R, Deodhar AA, Wollenhaupt J, Khraishi M, Kielar D, Woltering F, Stach C, Hoepken B, Arledge T, van der Heijde D (2014) Effect of certolizumab pegol on signs and symptoms in patients with psoriatic arthritis: 24-week results of a Phase 3 double-blind randomised placebo-controlled study (RAPIDPsA). Ann Rheum Dis 73(1):48-55. https://doi.org/10.1136/annrh eumdis-2013-203696

10. Maksymowych WP, Mallon C, Morrow S, Shojania K, Olszynski WP, Wong RL, Sampalis J, Conner-Spady B (2009) Development and validation of the Spondyloarthritis Research Consortium of Canada (SPARCC) enthesitis index. Ann Rheum Dis 68(6):948953. https://doi.org/10.1136/ard.2007.084244

11. Wells G, Becker JC, Teng J, Dougados M, Schiff M, Smolen J, Aletaha D, van Riel PL (2009) Validation of the 28-joint Disease Activity Score (DAS28) and European League Against Rheumatism response criteria based on C-reactive protein against disease progression in patients with rheumatoid arthritis, and comparison with the DAS28 based on erythrocyte sedimentation rate. Ann Rheum Dis 68(6):954-960. https://doi.org/10.1136/ ard.2007.084459

12. Salaffi F, Ciapetti A, Carotti M, Gasparini S, Gutierrez M (2014) Disease activity in psoriatic arthritis: comparison of the discriminative capacity and construct validity of six composite indices in a real world. Biomed Res Int 2014:528105. https://doi. org/10.1155/2014/528105

13. Blackmore MG, Gladman DD, Husted J, Long JA, Farewell VT (1995) Measuring health status in psoriatic arthritis: the health assessment questionnaire and its modification. J Rheumatol 22(5):886-893

14. Aletaha D, Smolen J (2005) The simplified disease activity index (SDAI) and the clinical disease activity index (CDAI): a review of their usefulness and validity in rheumatoid arthritis. Clin Exp Rheumatol 23(5 Suppl 39):S100-S108

15. Schoels M, Aletaha D, Funovits J, Kavanaugh A, Baker D, Smolen JS (2010) Application of the DAREA/DAPSA score for assessment of disease activity in psoriatic arthritis. Ann Rheum Dis 69(8):1441-1447. https://doi.org/10.1136/ard.2009.122259

16. Zhang W, Bansback N, Boonen A, Young A, Singh A, Anis AH (2010) Validity of the work productivity and activity impairment questionnaire-general health version in patients with rheumatoid 
arthritis. Arthritis Res Ther 12(5):R177. https://doi.org/10.1186/ $\operatorname{ar} 3141$

17. Reilly MC, Gooch KL, Wong RL, Kupper H, van der Heijde D (2010) Validity, reliability and responsiveness of the work productivity and activity impairment questionnaire in ankylosing spondylitis. Rheumatology (Oxford) 49(4):812-819. https://doi. org/10.1093/rheumatology/kep457

18. Haglund E, Petersson IF, Bremander A, Bergman S (2015) Predictors of presenteeism and activity impairment outside work in patients with spondyloarthritis. J Occup Rehabil 25(2):288-295. https://doi.org/10.1007/s10926-014-9537-2

19. Gottlieb A, Korman NJ, Gordon KB, Feldman SR, Lebwohl M, Koo JY, Van Voorhees AS, Elmets CA, Leonardi CL, Beutner KR, Bhushan R, Menter A (2008) Guidelines of care for the management of psoriasis and psoriatic arthritis: section 2. Psoriatic arthritis: overview and guidelines of care for treatment with an emphasis on the biologics. J Am Acad Dermatol 58(5):851-864. https://doi.org/10.1016/j.jaad.2008.02.040

20. Lyu R, Govoni M, Ding Q, Black CM, Kachroo S, Fan T, Ogbonnaya A, Donga P, Hill J, Makin C (2016) Treatment persistence among patients with rheumatoid disease (RA, AS, PsA) treated with subcutaneous biologics in Germany. Rheumatol Int 36(1):143-153. https://doi.org/10.1007/s00296-015-3348-4

21. Calip GS, Adimadhyam S, Xing S, Rincon JC, Lee WJ, Anguiano RH (2017) Medication adherence and persistence over time with self-administered TNF-alpha inhibitors among young adult, middle-aged, and older patients with rheumatologic conditions. Semin Arthritis Rheum 47(2):157-164. https://doi.org/10.1016/j. semarthrit.2017.03.010

22. Bonafede M, Fox KM, Watson C, Princic N, Gandra SR (2012) Treatment patterns in the first year after initiating tumor necrosis factor blockers in real-world settings. Adv Ther 29(8):664-674. https://doi.org/10.1007/s12325-012-0037-5

23. Palmer JB, Li Y, Herrera V, Liao M, Tran M, Ozturk ZE (2016) Treatment patterns and costs for anti-TNF $\alpha$ biologic therapy in patients with psoriatic arthritis. BMC Musculoskelet Disord 17:261. https://doi.org/10.1186/s12891-016-1102-z

24. Stober C, Ye W, Guruparan T, Htut E, Clunie G, Jadon D (2018) Prevalence and predictors of tumour necrosis factor inhibitor persistence in psoriatic arthritis. Rheumatology (Oxford) 57(1):158 163. https://doi.org/10.1093/rheumatology/kex387

25. Busard CI, Cohen AD, Wolf P, Gkalpakiotis S, Cazzaniga S, Stern RS, Hutten BA, Feldhamer I, Quehenberger F, Lichem R, Kojanova M, Adenubiova E, Addis A, Naldi L, Spuls PI (2018) Biologics combined with conventional systemic agents or phototherapy for the treatment of psoriasis: real-life data from PSONET registries. J Eur Acad Dermatol Venereol 32(2):245-253. https:// doi.org/10.1111/jdv.14583

26. Iannone F, Lopriore S, Bucci R, Lopalco G, Chiala A, Cantarini L, Lapadula G (2016) Longterm clinical outcomes in 420 patients with psoriatic arthritis taking anti-tumor necrosis factor drugs in real-world settings. J Rheumatol 43(5):911-917. https://doi. org/10.3899/jrheum.151042

27. Iannone F, Lopriore S, Bucci R, Scioscia C, Anelli MG, Notarnicola A, Lapadula G (2015) Two-year survival rates of anti-TNFalpha therapy in psoriatic arthritis (PsA) patients with either polyarticular or oligoarticular PsA. Scand J Rheumatol 44(3):192199. https://doi.org/10.3109/03009742.2014.962081

28. Iannone F, Santo L, Anelli MG, Bucci R, Semeraro A, Quarta L, D’Onofrio F, Marsico A, Carlino G, Casilli O, Cacciapaglia F, Zuccaro C, Falappone PC, Cantatore FP, Muratore M, Lapadula G (2017) Golimumab in real-life settings: 2 years drug survival and predictors of clinical outcomes in rheumatoid arthritis, spondyloarthritis, and psoriatic arthritis. Semin Arthritis Rheum 47(1):108-114. https://doi.org/10.1016/j.semarthrit.2017.01.008
29. Iannone F, Santo L, Bucci R, Semeraro A, Carlino G, Paoletti F, Quarta L, Leucci P, Zuccaro C, Marsico A, Scioscia C, D'Onofrio F, Mazzotta D, Muratore M, Cantatore FP, Lapadula G (2018) Drug survival and effectiveness of ustekinumab in patients with psoriatic arthritis. Real-life data from the biologic Apulian registry (BIOPURE). Clin Rheumatol 37(3):667-675. https://doi. org/10.1007/s10067-018-3989-2

30. Saad AA, Ashcroft DM, Watson KD, Hyrich KL, Noyce PR, Symmons DP (2009) Persistence with anti-tumour necrosis factor therapies in patients with psoriatic arthritis: observational study from the British Society of Rheumatology Biologics Register. Arthritis Res Ther 11(2):R52. https://doi.org/10.1186/ar2670

31. Fagerli KM, Kearsley-Fleet L, Watson KD, Packham J, BSRBRRA Contributors Group, Symmons DPM, Hyrich KL (2018) Long-term persistence of TNF-inhibitor treatment in patients with psoriatic arthritis. Data from the British Society for Rheumatology Biologics Register. RMD open 4(1):e000596. https:// doi.org/10.1136/rmdopen-2017-000596

32. Glintborg B, Ostergaard M, Dreyer L, Krogh NS, Tarp U, Hansen MS, Rifbjerg-Madsen S, Lorenzen T, Hetland ML (2011) Treatment response, drug survival, and predictors thereof in 764 patients with psoriatic arthritis treated with antitumor necrosis factor alpha therapy: results from the nationwide Danish DANBIO registry. Arthritis Rheum 63(2):382-390. https://doi.org/10.1002/art.30117

33. Hojgaard P, Ballegaard C, Cordtz R, Zobbe K, Clausen M, Glintborg B, Kristensen LE, Dreyer L (2018) Gender differences in biologic treatment outcomes-a study of 1750 patients with psoriatic arthritis using Danish Health Care Registers. Rheumatology (Oxford) 57(9):1651-1660. https://doi.org/10.1093/ rheumatology/key 140

34. Ballegaard C, Højgaard P, Dreyer L, Cordtz R, Jørgensen TS, Skougaard M, Tarp S, Kristensen LE (2018) Impact of comorbidities on tumor necrosis factor inhibitor therapy in psoriatic arthritis: a population-based cohort study. Arthritis Care Res (Hoboken) 70(4):592-599. https://doi.org/10.1002/acr.23333

35. Glintborg B, Gudbjornsson B, Krogh NS, Omerovic E, Manilo N, Holland-Fischer M, Lindegaard HM, Loft AG, Nordin H, Johnsen L, Oeftiger SF, Hansen A, Rasmussen C, Grondal G, Geirsson AJ, Hetland ML (2014) Impact of different infliximab dose regimens on treatment response and drug survival in 462 patients with psoriatic arthritis: results from the nationwide registries DANBIO and ICEBIO. Rheumatology (Oxford) 53(11):2100-2109. https://doi.org/10.1093/rheumatology/keu25 2

36. Aaltonen K, Heinonen A, Joensuu J, Parmanne P, Karjalainen A, Varjolahti-Lehtinen T, Uutela T, Puurtinen-Vilkki M, Arstila L, Blom M, Sokka T, Nordstrom D (2017) Effectiveness and drug survival of TNF-inhibitors in the treatment of psoriatic arthritis: a prospective cohort study. Semin Arthritis Rheum 46(6):732-739. https://doi.org/10.1016/j.semarthrit.2016.09.005

37. Heiberg MS, Koldingsnes W, Mikkelsen K, Rodevand E, Kaufmann C, Mowinckel P, Kvien TK (2008) The comparative oneyear performance of anti-tumor necrosis factor alpha drugs in patients with rheumatoid arthritis, psoriatic arthritis, and ankylosing spondylitis: results from a longitudinal, observational, multicenter study. Arthritis Rheum 59(2):234-240. https://doi. org/10.1002/art.23333

38. Kristensen LE, Gulfe A, Saxne T, Geborek P (2008) Efficacy and tolerability of anti-tumour necrosis factor therapy in psoriatic arthritis patients: results from the South Swedish Arthritis Treatment Group register. Ann Rheum Dis 67(3):364-369. https://doi. org/10.1136/ard.2007.073544

39. Svedbom A, Dalén J, Black CM, Kachroo S (2017) Persistence and costs with subcutaneous TNF-alpha inhibitors in immunemediated rheumatic disease stratified by treatment line. Patient 
Prefer Adherence 11:95-106. https://doi.org/10.2147/PPA.S1198 08

40. Huynh DH, Boyd TA, Etzel CJ, Cox V, Kremer J, Mease P, Kavanaugh A (2017) Persistence of low disease activity after tumour necrosis factor inhibitor (TNFi) discontinuation in patients with psoriatic arthritis. RMD Open 3(1):e000395. https://doi. org/10.1136/rmdopen-2016-000395

41. Harrold LR, Stolshek BS, Rebello S, Collier DH, Mutebi A, Wade SW, Malley W, Greenberg JD, Etzel CJ (2017) Impact of prior biologic use on persistence of treatment in patients with psoriatic arthritis enrolled in the US Corrona registry. Clin Rheumatol 36(4):895-901. https://doi.org/10.1007/s10067-017-3593-x

42. Mease PJ, Collier DH, Saunders KC, Li G, Kremer JM, Greenberg JD (2015) Comparative effectiveness of biologic monotherapy versus combination therapy for patients with psoriatic arthritis: results from the Corrona registry. RMD open 1(1):e000181. https ://doi.org/10.1136/rmdopen-2015-000181

43. Mease PJ, Lesperance T, Liu M, Collier DH, Mason M, Deveikis S, Accortt NA (2017) Changes in treatment patterns in patients with psoriatic arthritis initiating biologic and nonbiologic therapy in a clinical registry. J Rheumatol 44(2):184-192. https://doi. org/10.3899/jrheum.160343

44. Kristensen LE, Geborek P, Saxne T (2009) Dose escalation of infliximab therapy in arthritis patients is related to diagnosis and concomitant methotrexate treatment: observational results from the South Swedish Arthritis Treatment Group register. Rheumatology (Oxford) 48(3):243-245. https://doi.org/10.1093/rheum atology/ken 467
45. Luber AJ, Tsui CL, Heinecke GM, Lebwohl MG, Levitt JO (2014) Long-term durability and dose escalation patterns in infliximab therapy for psoriasis. J Am Acad Dermatol 70(3):525-532. https ://doi.org/10.1016/j.jaad.2013.10.059

46. Romero-Jimenez RM, Escudero-Vilaplana V, Baniandres Rodriguez O, Garcia Martin E, Mateos Mayo A, Sanjurjo Saez M (2018) Association between clinical factors and dose modification strategies in the treatment with ustekinumab for moderateto-severe plaque psoriasis. J Dermatol Treat 29(8):792-796. https ://doi.org/10.1080/09546634.2018.1466978

47. Feldman SR, Zhao Y, Zhou H, Herrera V, Tian H, Li Y (2017) Economic impact of above-label dosing with etanercept, adalimumab, or ustekinumab in patients with psoriasis. J Manag Care Spec Pharm 23(5):583-589. https://doi.org/10.18553/ jmcp.2017.23.5.583

48. Schwartzman S, Li Y, Zhou H, Palmer JB (2017) Economic impact of biologic utilization patterns in patients with psoriatic arthritis. Clin Rheumatol 36(7):1579-1588. https://doi. org/10.1007/s10067-017-3636-3

Publisher's Note Springer Nature remains neutral with regard to jurisdictional claims in published maps and institutional affiliations. 